\title{
SpineCor in the treatment of adult scoliosis
}

\author{
Louise Marcotte \\ From 7th International Conference on Conservative Management of Spinal Deformities \\ Montreal, Canada. 20-22 May 2010
}

\section{Introduction}

Adult patients with scoliosis are offered little hope for rehabilitation and pain relief by health care professionals. Long term use of AINS and pain medication has proven harmful; rigid bracing is only rarely used due to its often disappointing results; surgery is only reserved for the most serious cases and mainly to preserve vital functions. Conservative management has also had poor outcome often due to long-term patient compliance.

Long-term treatment of Adult Scoliosis with The SpineCor Pain Relief Back Brace deserves more attention. SpineCor offers a wide variety of combinations to improve posture. Its primary therapeutic goal is the relief of pain while reducing the mechanical strain on the neuromusculoskeletal system, which would only with time, aggravate of the condition. The brace acts as a dynamic support to offload the spinal joints, therefore protecting the misaligned spine from the compressive forces of gravity, while the resistive elastic bands reinforce the core musculature to an overall better postural alignment.

\section{Methods}

A preliminary long-term study was made on 30 adult scoliosis patients, 26 females and 4 males, aged between 18 and 69. All suffered enough chronic back pain to seek treatment and were fitted with a SpineCor Pain Relief Back Brace according to the SpineCor Protocol. The data over an 18 to 28 months time frame was collected while the patients were actively wearing their brace anywhere from 10 to 130 hours/week.

\section{Results}

The overall improvement in the perception of pain by the adult scoliotic patients was $77 \%$, and appeared to remain stable with time $(78 \%, 83 \%$ and $76 \%$ on

OrthoPosturology and Scoliosis Institute, Montreal, Canada

Full list of author information is available at the end of the article subsequent visits). Half of them reported having complete resolution of their symptoms.

Although the brace had no significant effect on reducing the pathological curvature of the spine, as would be expected in mature skeletons, it was subjectively noticed both by the evaluator and the patient themselves that they had a better overall postural alignment while they were wearing their brace.

\section{Conclusion}

These results suggest that the SpineCor Pain relief Back Brace is a promising conservative method for the longterm management of scoliosis in the adult population as it significantly reduces their pain status and improves their wellbeing

Published: 10 September 2010

doi:10.1186/1748-7161-5-S1-047

Cite this article as: Marcotte: SpineCor in the treatment of adult scoliosis. Scoliosis 2010 5(Suppl 1):O47.

Submit your next manuscript to BioMed Central and take full advantage of:

- Convenient online submission

- Thorough peer review

- No space constraints or color figure charges

- Immediate publication on acceptance

- Inclusion in PubMed, CAS, Scopus and Google Scholar

- Research which is freely available for redistribution 